\title{
Transition from being OK to NOT OK with tooth loss among a selection of older people in Iran: a qualitative study
}

\author{
Shahin Dezhdar ${ }^{1}$, Najmeh Fereidoonpoor ${ }^{2}$, Ehsan Mostaghni ${ }^{3}$, Faezeh Jahanpour ${ }^{4}$ and \\ Maryam Ravanipour ${ }^{5}$ \\ ${ }^{1}$ Student Research Committee, Bushehr University of Medical Sciences, Bushehr, Iran; ${ }^{2}$ Department of Prosthodontics, School of Dentistry, \\ Bushehr University of Medical Sciences, Bushehr, Iran; ${ }^{3}$ Department of Periodontics, School of Dentistry, Bushehr University of Medical \\ Sciences, Bushehr, Iran; ${ }^{4}$ Faculty of Nursing and Midwifery, Bushehr University of Medical Sciences, Bushehr, Iran; ${ }^{5}$ The Persian Gulf \\ Tropical Medicine Research Center, Bushehr University of Medical Sciences, Bushehr, Iran
}

Gerodontology 2016; doi: 10.1111/ger.12251

Transition from being OK to NOT OK with tooth loss among a selection of older people in Iran: a qualitative study

Background: Several studies have covered oral health and dental decay in old age, but these studies mostly applied standard quantitative tools and did not include consideration of older people's views on oral problems, partial edentulism in particular.

Objective: To explore people's perceptions in terms of the transition from being OK to NOT OK with tooth loss among a selection of older people in Iran.

Materials and methods: A qualitative content analysis study was chosen for the research by interviewing 15 older people using open-ended questions. Criteria for participation in the study were as follows: fitting the Kennedy class I or class I modification I category, having a minimum of four teeth but not more than 20 and being aged 60 years or more. The recorded interviews were then transcribed, and a coding process was applied based on a qualitative, conventional content analysis.

Results: The four main themes that emerged were as follows: (i) gradual realisation of the need to deal with the problem; (ii) the search for information on dental health; (iii) the challenge of adaptation; and (iv) tendency towards dental rehabilitation.

Conclusion: The turning point in the transition from being OK to NOT OK seemed to be associated with an edentulous crisis that had occurred from another problem such as stomach ache, distention, or nocturnal dyspnoea due to swallowing food that had not been properly chewed and had an affect on an elderly person's life, physically and mentally. It is important to recognise the concept of healthy eating in relation to edentulism.

Keywords: qualitative research, Iran, age, dental diseases, edentulous mouth, dental care for the aged.

Accepted 24 September 2016

\section{Introduction}

Ageing is a bio-psycho-social process that differs among individuals according to their health status, culture and lifestyle ${ }^{1}$. People experience more changes in their bodies as they approach old age than during other stages of life and they need to develop the ability and flexibility to cope with such changes ${ }^{2}$. The biological changes involved in ageing such as smooth muscle weakness and skeletal muscle atrophy, osteoporosis and fragility of bones and teeth are age-related conditions and as such not considered as illnesses. Nevertheless, changes that occur with ageing do limit performance of the body's organs and tissue; and loss of teeth is an important change ${ }^{2,3}$.

Cases of complete edentulism have decreased in the last few decades; however, more than onethird of people over 60 still suffer from partial edentulism ${ }^{4}$. Partial edentulism is defined as the absence of some but not all of one's natural teeth in a dental $\operatorname{arch}^{5}$. Missing one to 15 teeth in one jaw is known as partial edentulism ${ }^{6}$. Current estimates indicate that $71.5 \%$ of people aged between 65 and 74 suffer from partial edentulism (with an average of 18.9 remaining teeth $)^{7}$. In a study of 
edentulism on 600 individuals over the age of 30 in the city of Yazd in Iran demonstrated that prevalence of Kennedy free ending partial edentulism increased among individuals during the ageing process $^{8}$. Many older people have been socialised to expect deteriorating health as they approach old age 9 . A qualitative study of 38 elderly people over the age of 65 years with at least four remaining teeth determined that having natural teeth had a positive effect on quality of $\operatorname{life}^{10}$. Some older people expressed the opinion that in terms of oral health, having one's natural teeth meant not suffering from the pain and infection caused by a prosthesis so are better able to perform their social role and related activities ${ }^{11}$. Many studies have reported that loss of natural teeth disturbs quality of life in elderly people ${ }^{12-14}$. Furthermore, the findings of a study on 465 participants aged 65 years and above in Spain highlighted that age must be considered as a risk factor for malnutrition ${ }^{15}$.

As mentioned earlier, several studies have reported on dental decay and quality of life related to loss of teeth but these were most commonly conducted with standard quantitative investigative techniques, using tools. Such tools mostly emphasise the negative effects of oral disorders, so the positive effects of having one's natural teeth can have on quality of life have been largely overlooked in these studies and application of tools for analysis have not identified positive or neutral viewpoints related to oral health or how people may feel at having lost some of their teeth (OK or not OK?). For example, most people had not considered missing a social opportunity until they had experienced losing all their front teeth. This can be due to changes in perception of health during old age, or because of an increase in adaptive skills during this period. Moreover, people of a particular generation, such as the war generation, may have experienced exceptional difficulties during their lives that facilitate easier adaptation to the changes that occur with old age compared to younger peo$\mathrm{ple}^{10}$. In addition, more than half of all older adults rely on dentures, partial or full, which may not be worn regularly due to discomfort or poor conditions ${ }^{2}$. Another study highlighted different perceptions between people with complete and partial edentulism and those who still had most of their teeth; research indicated that those that had maintained their natural set of teeth had a sense of pride and were pleased that they did not need to cope with dentures and that those who had lost their teeth often regretted their loss but were glad that they did not have to be concerned with the problems associated with having one's own teeth ${ }^{16}$.

It is very important for dentists and clinicians to have a good understanding of the process of losing teeth and its consequences ${ }^{17}$. In order to provide patients with the right treatment, dentists need to be aware of a patient's motive in choosing a certain type of treatment and for careful consideration of a patient's particular set of problems before treatment, including the transition to edentulism ${ }^{18,19}$. Primarily, there needs to be a deep recognition of partial edentulism taken with consideration of the points of view of the elderly people themselves, as partial edentulism is probably a transitional phase between having a complete set of teeth and that of complete edentulism. As answers to the structured questionnaire may have reflected researchers' assumptions, participants' feelings may not have been clearly expressed. Therefore, the aim of this study was to explore perceptions of the transition from being $\mathrm{OK}$ to not $\mathrm{OK}$ with tooth loss among a selection of older people in Iran.

\section{Materials and methods}

This qualitative study was carried out in 2014 using the conventional content analysis approach. Content analysis as a research method is a normative reasonable method for describing a phenomenon ${ }^{20}$. In this study, based on the literature and our research team's experiences, especially the dental specialists, and the majority of complete edentulous patient who have their missing teeth substituted with complete denture or implant supported dentures or have adapted to their edentulism, our research was aimed to explore the effect of missing teeth in the group of partial edentulous older people who did not restore their missing teeth. The participants were 15 elderly individuals ( 10 women and five men) within the age range of $60-83$ years. To participate in this study, inclusion criteria were as follows:

1. Be at least 60 years old

2. Falling into Kennedy class I or class I modification I category

3. Minimum number of remaining teeth: four, two pair of occluding teeth

4. Maximum number of remaining teeth: 20 which includes 12 anterior teeth and eight premolars (shortened arch patients)

5. Have the ability and tendency to express their experiences and feelings. 
Exclusion criteria include not willing to participate in the study, or refusal to continue with the interviews. According to various studies ${ }^{21-23}$, patients with shortened arch dentition have the same efficacy of mastication as those individuals having all their molar teeth, we considered individuals to have shortened arch dentition as our upper limit due to the fact that these individuals presumably characterise the same mastication efficacy as normal people. All our participants belong to either Kennedy class I or class I modification.

The elderly participants of this study were selected according to the mentioned inclusion and exclusion criteria. Initially, we selected some participants from healthcare centres or dental clinics as convenience sampling because there is no follow-up dentistry system in Iran. To gather more participants, a snow ball sampling method was utilised with participants offering names of additional older people. All the participants were from Iranian cities of Bushehr and Isfahan. The interviews were carried out by a female researcher with 10 years of experience as an adult gerontology nurse practitioner. The interviewer had no care providing role in this study. These interviews were all performed under the direct supervision of nursing professors with an expertise in qualitative research and gerontology with advice and assistance of other dental specialists in the study.

Finally, all interviews were carried out in a private place that was convenient for the participants; which was mostly in the participants' houses or dental office. Maximum variation in sampling in terms of socio-economic status, education, having a spouse and children were considered to include participants with a wide range of experiences and perspectives.

After calling and giving them a brief explanation of the primary goals of the study, by receiving verbal approval for their cooperation in the project, appropriate time and place were determined by participants. On the day of the interview, the researcher came to the study's environments where participants' houses or dental office were mainly located. Before starting the interview, the researcher, with respect to samples, established a proper communication with participants; thereafter, the aims of the study, confidentiality of the information and the recording of the interview were explained to them. The method of data collection in the study was semi-structured personal interview. After obtaining written consent, the interview started with open questions which were determined in special panels such as 'how do you feel without some of your teeth?' or based on your experiences, how do you deal with losing some of your teeth?' and 'what steps have you taken to face this issue?', and based on their answers to these questions, more profound, complementary questions were asked to clarify the issue like "what do you mean by this? Can you explain more about this?' as probing and searching questions.

The duration of the interview varied based on the participants' tolerance and preferences from 30 to 80 min with the mean of $55 \mathrm{~min}$. As most of the participants were old and lacked the patience for long interviews, these interviews were carried out in two or more separate sessions. In all, 32 interviews were carried out with 15 participants. Moreover, we faced some negative cases (two widows) who talked about the role of edentulism in marital relationships which were not confirmed in further interviews with other widows or married participants.

All the interviews were recorded with an MP3 player. After conducting each interview, the text was transcribed verbatim and then $\operatorname{coded}^{20}$. Data analysis was carried out using the constant comparison technique and the Graneheim and Lundman's qualitative content analysis approach. Accordingly, we took the following five steps to analyse the data: (i) transcribing the whole interview immediately after conducting it; (ii) reading the whole transcript to obtain a general understanding of it; (iii) identifying meaning units and primary codes; (iv) categorising similar codes into main categories; and (v) identifying the main themes of the categories ${ }^{24}$.

In our study, from the 12th interview, we did ot receive further information and the previous codes were repeated; despite this, we still interviewed three more participants from healthcare centres and dental clinics. So when no new information of further importance was added from the last few interviews and data saturation was reached, we stopped sampling. Sample size in qualitative studies depends on required information $^{25}$ and is often low ${ }^{26}$.

Two experts in qualitative analysis and subject matter (SD and MR) performed the peer checking for each transcript and confirmed that $85 \%$ of codes and categories were accurate; in the case of discrepancies and different interpretation between researchers, several panels made of all the research team examined the coding process to agree upon a final version. To increase the trustworthiness and rigour of data, the researchers devoted time to collect the information. The first author had long experience of providing care to 
older peoples, and hence, the criterion of prolonged engagement with the subject matter of the study was fulfilled. It means the pre-understanding of the older people's situation in general by the interviewer, because of many years of clinical work with edentulism patients, made it easier to ask the appropriate follow-up questions. Besides, the interviewer (SD) was a nurse practitioner with 10 years of experience as an adult/gerontology, two of the researchers (MR and FJ) were associate professor in nursing and expert in qualitative studies, especially content analysis and studying on older people, and two of the researchers were specialist in dentistry (NF; prosthodontist, and EM; Periodontist). We neither had pre-assumed conceptual framework for the study nor did we use available definitions and theories in the area of edentulism. Meanwhile, we were focused on the aim of the research, maximum use of people with various socio-economic conditions and avoidance of inducing questions; and we tried to coordinate with the participants to have similar conclusions by submerging in the data and coming to an agreement with encodings. All the research team were involved in the data analysis process, and several panels discussed the data and codes with complementary ideas as peer check until they came to an agreement ${ }^{20}$. Besides, we presented the findings to three older people with partial edentulism who had not participated in the study so as to establish transferability. They confirmed that our findings fitted their experiences.

\section{Ethical considerations}

Research Committee of the Bushehr University of Medical Sciences approved this study (ref: 2013/ 71-76-95). The aims of the study were explained to all the participants of the study, and they were told that their name and identity will remain confidential and only a short part of their sayings will be cited in the report, and they can leave the study whenever they want without any adverse outcome. They were assured of confidentiality of records and transcriptions. All the participants gave their informed oral and written consent for participating in the study.

\section{Results}

A total of 15 elders (10 women and five men), with the mean age of 68.8 ranging from 60 to 83 years and median number of 10 teeth in the mouth, participated in the study. Majority of the participants had primary education (Table 1). A total of eight subcategories and four themes were obtained from the data analysis on the elders' perception of partial edentulism (Table 2). These four themes are as follows:

1. Gradual realisation for dealing with the problem

2. The search for information on dental health

3. Challenge of adaptation

4. A tendency towards dental rehabilitation

\section{Gradual realisation for dealing with the problem}

It seemed that although most of the aged participants of this study had lost their first teeth 1520 years earlier, due to gradual loss, they did not consider it a threat to their health, and now at old age, this had made them perceive edentulism as a problem with the delay. According to the expressed experiences of the aged people, this delayed perception had been obtained from two subcategories of (i) continuity in the normal routine of life and (ii) life priority perception.

Continuity in the natural routine of life means the elders continue to live in different physical, mental and social aspects despite their gradual loss of teeth. Regarding physical aspect, the old people said that with gradual teeth loss, they had the ability to eat with the remaining teeth. In this regard, a 60-year-old lady said 'I eat everything; I eat with my remaining teeth..' (Participant 7). Moreover, regarding the mental aspect, although before coming to this stage of edentulism, most of the aged people had lost their first teeth 1520 years earlier, they had not thought of this gradual loss of teeth as a threat to life (health); therefore, they continued with their natural routine of life. A 64-year-old lady who had visited a dentist answered the question 'did you do anything when you lost your first teeth?' she said 'no, then my teeth status was not so bad' (Participant 6). These words imply that this person has 'recently' thought of this status as a problem. In other words, the participants' statements could imply that losing the first teeth and replacing the functions of the lost teeth with those of the remaining teeth and being careless to their oral health would result to a gradual and further loss of teeth in the mouth. As a result, they would not be able to predict the extent of edentulism and the follow-up problems. Now they talk of their teeth in such a way that indicates they have tied their general health with having teeth. Besides, it seems the elders who had more teeth remaining in their mouth or had lower social 
Table 1 Demographic characteristics of the participants.

\begin{tabular}{lllllrc}
\hline Participant number & Sex & Age & Level of education & Job & $\begin{array}{c}\text { Number of teeth } \\
\text { in mandible }\end{array}$ & $\begin{array}{c}\text { Number of teeth } \\
\text { in maxilla }\end{array}$ \\
\hline 1 & Male & 75 & Elementary & Building Plumbers & 2 & 2 \\
2 & Female & 71 & Elementary & Housewife & 8 & 10 \\
3 & Female & 83 & Illiterate & Housewife & 4 & 6 \\
4 & Female & 77 & Illiterate & Housewife & 6 & 9 \\
5 & Female & 60 & Elementary & Housewife & 9 & 9 \\
6 & Female & 64 & B. Sc. & Retired nurse & 4 & 4 \\
7 & Female & 60 & Elementary & Carpet weaver & 4 & 2 \\
8 & Female & 60 & Diploma & Hairdresser & 7 & 5 \\
9 & Female & 71 & Elementary & Housewife & 5 & 4 \\
10 & Male & 63 & Elementary & Self-employed & 5 & 6 \\
11 & Female & 65 & B.Sc. & Retired teacher & 7 & 5 \\
12 & Male & 68 & Diploma & Retired clerk & 5 & 5 \\
13 & Male & 67 & Diploma & Self-employed & 8 & 7 \\
14 & Female & 73 & B.Sc. & Retired clerk & 5 & 3 \\
15 & Male & 69 & Elementary & Self-employed & 4 & 5 \\
\hline
\end{tabular}

Table 2 Process of data analysis and the construction of themes.

\begin{tabular}{|c|c|c|}
\hline Theme & Categories & Subcategories \\
\hline $\begin{array}{l}\text { Gradual realisation } \\
\text { of the need to } \\
\text { deal with the problem }\end{array}$ & $\begin{array}{l}\text { Continuity in the normal } \\
\text { routine of life } \\
\text { Life priority perception }\end{array}$ & $\begin{array}{l}\text { Ability to chew for years after losing their first tooth } \\
\text { Lack of threat or problem after losing their first tooth } \\
\text { Perception of edentulism as a natural part of ageing } \\
\text { Addressing the religious and spiritual preferences } \\
\text { of old age } \\
\text { Commitment to charity, compared to follow-up of } \\
\text { dental treatment } \\
\text { Low estimation of edentulous problems compared } \\
\text { to other problems }\end{array}$ \\
\hline $\begin{array}{l}\text { The search for } \\
\text { information on } \\
\text { dental health }\end{array}$ & $\begin{array}{l}\text { Reflection on the causes } \\
\text { of edentulism } \\
\text { Analysis of dental health } \\
\text { information }\end{array}$ & $\begin{array}{l}\text { Effect of specific diseases on dental decay } \\
\text { Effect of repeated deliveries on tooth loss } \\
\text { Gain appropriate knowledge about dental health } \\
\text { Appropriate knowledge of dental health care }\end{array}$ \\
\hline $\begin{array}{c}\text { Challenge of } \\
\text { adaptation }\end{array}$ & $\begin{array}{l}\text { Edentulism crisis } \\
\text { Strives to manage edentulism } \\
\text { problems }\end{array}$ & $\begin{array}{l}\text { Distention and nocturnal dyspnoea due to swallowing } \\
\text { partially chewed food } \\
\text { Self-censorship eating } \\
\text { Changing eating habits through chipping, overcooking } \\
\text { and conserving food } \\
\text { Taking painkillers to relieve the pain }\end{array}$ \\
\hline $\begin{array}{l}\text { Tendency towards } \\
\text { dental rehabilitation }\end{array}$ & $\begin{array}{l}\text { Motivation for treatment } \\
\text { Strives to choose the type and } \\
\text { time of treatment }\end{array}$ & $\begin{array}{l}\text { Feelings of embarrassment because of edentulism } \\
\text { Tendency to be better able to eat favourite foods } \\
\text { Desire to improve social status by restoring damaged } \\
\text { teeth } \\
\text { Expensive dental treatment } \\
\text { Sense of frustration about the use of dentures } \\
\text { Gingival ulcerating when getting fatter or thinner } \\
\text { using a denture }\end{array}$ \\
\hline
\end{tabular}

level or had several edentulous peers had less problems with their tooth loss and did not realise this issue as a threat to their overall health; but overall, gradual side effects of tooth loss had trigger their minds that something wrong had happened to their chewing ability.

Some aged widows had implied that pursuing their debt problems is not important due to the 
death of their husbands, but it was not confirmed by other widows. It seemed that in marital aspect, most of the aged men and women had implied that edentulism had no effect on their close relationship with their spouses and had not changed it in any way. In this regard, a 71-year-old woman said 'no, no, no effect. Thank God our relationship is the same as before. We have been living together for 52 years' (Participant 9). Another 65-year-old participant said 'my husband says "don't worry, the tooth is not important, I don't have too"' (Participant 11). Furthermore, in relation to the social aspect, the elderly maintained their relationships with others as before, and they are rarely faced with problems in their relationship with and talking to others. To confirm this matter, an 83-year-old woman confidently said 'I have no problem in speaking with others, just the way I am talking to you right now' (Participant 3). It seemed that the aged people's indifference in the mentioned aspects had finally made them continue their routine life without feeling any threat.

Moreover, the second subcategory as perception of life priorities included some issues that were more important for the aged people, in such a way that even after realising the problems with tooth loss and its threats to their health mostly (with sense of regret and sadness) because of other priorities in their lives happened to them, it was not possible to them to pursue the treatment of their teeth. These issues mainly resulted from their culture, tradition and religious beliefs. Most of the aged people participating in this study stated the priority and importance of other things such as the children's education and marriage, provision of housing, pilgrimage, providing welfare services over treating the problem of losing their first teeth. Of course, it seems that financial and economic problems had been effective along with religious and cultural beliefs. In this regard, a 75-year-old man said if I see someone living with difficulty; and his or her child goes to school and he or she doesn't have house and money, I try to help them first so that they will be satisfied with me and consequently God will be satisfied with me; it is a priority for me in life' (Participant 1). Moreover, another 60-year-old woman who, despite her old age, wove carpet for subsistence and with having only six teeth took pilgrimage as her priority; and when she was asked about the reason of not treating her edentulism, she said 'I want to go on a pilgrimage, it is more important, I like it' (Participant 7). Besides cultural matters, some aged people knew that the treatment of all other diseases is more important that edentulism, and most of them did not think of edentulism as the most important in their lives. In this regard, an 83-year-old woman said 'I wanted to buy denture, but when I felt that I cannot see well, I said to my son that my teeth are not important at the moment, and I asked him to do something for my eyes; I told him that I can eat with my front teeth now but I can't do anything if I go blind' (Participant 3). Another 63-year-old man said 'first the heart is important, if the heart is healthy, we can treat our teeth later... if the heart doesn't work, what is the use of teeth? (Participant 10)'. Therefore, it can be inferred that these participants precept the importance of edentulism with more delay as they know the above-mentioned matters prior to this problem. However, there were many other older people who mentioned the causes of edentulism and mostly stressed their lack of sufficient knowledge on how to take proper care of their teeth since they were young.

\section{The search for information on dental health}

This theme can be described as searching for dental health information for better reflection and contemplating over the causes of edentulism. In fact, after realising the problems and consequences caused by tooth loss with delay in old age, blaming oneself for their failure and negligence of oral health in the past, they mostly scrutinised how and why their oral health had reduced at this low and threatening level. Then, they tried to acquire appropriate oral health information and analyse it in order to obtain a comprehensive view on their oral problems. This theme is made of two subcategories: (i) reflection on the causes of edentulism and (ii) analysis of dental health information.

Based on the statements made by the participants, majority of them despite many priorities in their lives had realised that their present dental health is problematic and confesses that they had little knowledge of dental oral health in their youth. They did not know the proper ways of keeping the mouth and teeth clean and healthy or how to prevent the teeth from decaying. This lack of sufficient knowledge on dental health had an effect on their views of dental health and they mainly applied traditional ways such as using salt and water to keep their teeth clean when they were young. In addition, the elderly women used to spend majority of their time on taking care of their children and as a result they would not pay much attention to their own health. Their health 
behaviours were also symptomatic to the problems, and they would use painkillers for dental pains, and when their teeth became loose, they would rather have them pulled out than seek proper treatments for the damaged teeth. After passing many years and becoming old, they faced a semi-empty mouth; they would consider this as a major health issue and were desperately trying to identify the causes of this problem. They would also partly blame this issue on their own unhealthy behaviours in the past such as excessive consumption of sweeties, not brushing the teeth, no attempts in maintaining oral dental hygiene and poor nutrition. A 77-year-old woman said 'I haven't taken proper care of my teeth. I had traditional beliefs. Even toothpaste could hardly be found in the past. We had been told that in order to keep our teeth clean and healthy we should use salt. Nevertheless, I would not usually wash my teeth when I was young. This eventually led to dental decay and loss (Participant 4)'. She further added 'I didn't properly take care of my teeth. When I had any pain in my teeth, I would take painkillers or gargle with warm salt water to soothe away the pain. I wouldn't go to dentist and if I had any loose teeth I would extract them (Participant 4)'. Another 73year-old female participant had this to say 'I'm sad for losing my teeth. Although not many dental service were present in the past, but my own negligence is also to blame. I kept stalling to take care of my teeth (Participant 14)'. On the other hand, most of the elderly participants mentioned the role of some external factors in losing their teeth. These factors include lack of modern healthcare and educational system, brushes and toothpastes not widely available, no dental health services in the past, parents negligence in instructing their children to keep their teeth healthy, financial issues and expensive dental services, diseases such as lupus, using drugs such as antidepressants, tooth type, pregnancy, childbirth or even the process of ageing. In this regard, a 69-year-old man said I have never smoked or used drugs. Losing my teeth has been due to using sugar or not brushing my teeth when I was young. And when I started to brush, my teeth had already decayed. My tooth structure and their composition were not also good' (Participant 15). Another 64-year-old retired woman said 'I always regret that I worked so much and got nervous, consequently I was affected by Lupus, so I had to take cortisone and as a result of that I lost my teeth... (Participant 6)' and another old lady said 'my toothache started after giving birth to my children, thereafter my teeth decayed and that made me have them pulled out (Participant 8)'.

Although some of the elderly participants in the study lacked sufficient knowledge on how to maintain dental hygiene, they were making attempts to analyse all the acquired information in order to gain appropriate knowledge about dental health, how to keep their other teeth healthy, what are the different treatments for lost teeth from media or their family and friends and they also try to educate their children and grandchildren about dental health. A 71-year-old female participant said 'In the past, I did not know the proper ways of taking care of my teeth but I have taught my children to brush their teeth after every meal so they won't run into the same problems that I had. I didn't pay much attention to my dental health. If I had taken proper care of my teeth, I would still have many of my teeth by now (Participant 2)'. Another 68-year-old participant said 'I have learned a lot from dentists' tips on TV and radio and I have told my children to brush their teeth constantly, so that their own children can learn how to keep their teeth healthy (Participant 12)'. It seems after analysing their different acquired information, and they tried to apply several mechanisms as adaptation strategies to manage the situation.

\section{Challenge of adaptation}

According to the statements of the participants, the challenge of adaptation involves edentulism problems and side effects, and the management of the problems caused by edentulism. This theme comprises two subcategories: (i) edentulism crisis and (ii) strives to manage edentulism problems.

It gradually seems that the potential side effects of edentulism become more significant for an elderly person who had adopted himself/herself to this problem before now, the consequences that affect the elderly person's life physically and mentally. Problems such as stomach ache, distention and nocturnal dyspnoea due to swallowing not well-chewed food led them to refrain from eating dinner. Moreover, feelings of general weakness due to inappropriate nutrition, reduction in chewing speed, feeling regret for inability to eat what others are eating and fumbling when speaking; all of these adverse effects had exposed the elders with an edentulous crisis. A 69-year-old man said 'my stomach has weakened since I cannot eat well, and I tremble when walking, so I should do something to chew better' (Participant 15). A 71year-old lady said 'since I can't keep up with the 
pace of eating with other members of the family, I don't eat with them anymore and prefer to eat alone (Participant 2)'. This statement can be interpreted as a way of self-censorship in eating as she seemed very desperate to find a way to deal with the problems caused by edentulism. But there seemed to be some differences among the elderly participants in terms of psychological and social adaptation. Among the participants, those who were more willing and eager to find a treatment or solution for their edentulism were the ones who more often discussed such issues as embarrassment during speaking or being self-conscious about their looks. On the other hand, the elderly participants who were not determined to receive treatment and also hung out with peers suffering from edentulism were the ones who deemed edentulism as a natural part of old age; although this finding demands further studies.

Striving to manage edentulism problems means that the elderly person has learned to gain physical and psychosocial control over edentulism. In the physical aspect, one tries to keep the maximum ability in eating with the remaining teeth and by changing the eating habits through chipping, mashing, dousing, overcooking, conserving and squeezing the food, one can manage and cope with eating inability to a great extent. In addition, some of them said they take painkillers to relieve the pain; some other elderly participants said that they use mask so that others do not notice their edentulism or cover their mouth with their hands. In mental aspect, the old person adapts himself/herself to edentulism by considering this problem to be a natural part of the ageing process and they believed that edentulism occurs to every person. In fact, it depicts a temporary or permanent regression to their first perception of edentulism as a natural process at old age, based on their ability on how to manage the side effects of edentulism. If they found an appropriate treatment based on their analysed information and affordability, they tended to pursue their treatment but if these prerequisites not met, they regressed to adapt to their edentulism. Even some elderly people think of edentulism as unimportant and common and compare themselves with others whose health conditions are worse. A 77year-old participant said 'when you grow old, you gradually lose everything; you will even lose strength in your hands and legs, let alone the teeth. I cannot walk if I don't wear my medical belt, there are other more important problems, and edentulism is not the only one (Participant $4)^{\prime}$. Another 83-year-old woman said 'edentulism is a part of everyone's life. Some people have worse problems than we do, I can still eat something with my remaining teeth' (Participant 3). In fact, losing teeth, especially when it affects participants' health, and nutritional status, brings about some disorders in elderly which needs some dental treatments.

\section{A tendency towards dental rehabilitation}

This category includes the aged person's severe involvement with intense tendency for the rehabilitation of dental performance. This matter leads to intense motivation of treatment; in addition, despite awareness of different treatment methods for dental problems, the old people were confused in choosing the type and time of treatment. Therefore, this theme consists of two subcategories: (i) motivation for treatment and (ii) strives to choose the type and time of treatment.

The consequences of edentulism crisis had motivated them to think about treatment. In other words, the aged person, for making decision, because of different challenges with edentulism side effects, was involved in a delayed thinking when faced with most of the daily problems of life; that is, the person would think whether he/she is able to do a certain thing or not. For instance, a 60-year-old woman said it is so bad, I like to go somewhere, to eat something, or to do something but I feel embarrassed, that is too bad (Participant 8)'. Of course, the consequences of edentulism crisis are the major causes of motivation for treatment. In some cases, preserving their beauty and encouragements from their spouses were the two factors that motivated the elderly participants to seek treatment. Some of them did not like to seek further treatment after the death of their spouse. In an answer to the question, why has she not performed anything to treat her teeth, a 60 -year-old woman said 'after the death of my husband, I had no motivation' (Participant 5), and another elderly participant said 'when my teeth decayed, my husband was not alive, that is good because he loved my teeth; if he were alive, he would feel sad and then try to help and comfort me' (Participant 6). Regarding beauty, she said 'I have to wear dentures, because the beauty of a face is so important, without the teeth, the face would look ugly' (Participant 6).

All the mentioned consequences make the aged person tend to regain his/her dental ability and seek a solution. 
Striving to choose the type and time of treatment includes searching for different treatment options to their situations, especially to find the right type and time of treatment. Majority of the elderly people were aware of different methods of treatment, for example crown, partial denture, implant and denture. But due to the advantages and disadvantages of each of these treatments, they were confused in choosing the right method. In this regard, a 60year-lady said 'partial denture is not good, it becomes wobbly, food and fruit seeds stuck under it, I don't like it; on the other hand, since my front teeth are ok I don't like to pull them out and wear denture, so I am currently adapting to them' (Participant 5). Another 60-year-lady said 'denture has so many problems; first I have to speak slowly, if I speak fast they will be thrown out, this is the biggest problem for a man or a woman...' (Participant 8). Some old people too, despite the many disadvantages they mentioned for a denture, thought that they have to use denture to keep their facial beauty and to overcome a part of their problem. Another old person said 'I have not thought about it yet, I am afraid if I have to wear denture, some of my problems may be gone' (Participant 14). They mentioned some disadvantages such as gingival ulcerating when getting fatter or thinner, not feeling the taste of food, the unpleasant sight of removing them and the fear of their falling out of mouth in front of others. Besides the type of treatment, several problems such as money, high cost and even severe pains of different dental services, and priority of all other issues in life had made the elderly people confused in choosing the appropriate time of treatment, and most of the time, they postpone it. A 69-yearold man with nine teeth who had gone to a dentist said 'I wanted to implant some years ago, the dentist said it would cost too much. But if I had money, I would implant (Participant 15)'.

\section{Discussion}

Four main themes emerged from interviews with the participants in this study: (i) gradual realisation of the need to deal with the problem; (ii) the search for information on dental health; (iii) the challenge of adaptation; and (iv) tendency towards dental rehabilitation. Self-perception of having partial edentulism was a gradual and delayed process. The elders, for various different reasons, including gradual loss of natural teeth, and perception the process of losing teeth as a natural part of ageing and despite difficultly eating some kinds of food, they were generally well adapted to their status and somehow satisfied with their nutritional status; and most of them had not pursued dental treatment until serious adverse effects of edentulism harmed their overall health. On experiencing the adverse effects of edentulism, otherwise known as an edentulous crisis, it was perceived as a lifethreatening condition and only then was dental rehabilitation pursued.

One of the major points of this study was the focus on people with only a few teeth and the problem of partial edentulism in people from different backgrounds who were yet to replace their missing teeth; those with recent experience of tooth loss or with different types and numbers of lost teeth in our study were not taken into consideration. Nevertheless, the nature of qualitative study, especially the limited number of subjects, prevents generalisation of these results.

In this study, the main finding consisted of a gradual realisation of how to deal with the problem of tooth loss, whereas 15-20 years ago, most of the participants had adapted to their edentulism and it was not considered as a problem or a threat to their general health. Furthermore, more than half of the aged in Brazil, despite poor clinical status of their teeth, considered themselves to have good oral health and some of them regarded dental problems as the result of ageing ${ }^{27}$. In a study on 92 people with edentulism aged 31-71, it was found that $55 \%$ of the subjects tolerated edentulism without any problems, while $45 \%$ could not accept it, but after more than 3 years after tooth loss, acceptance of edentulism increased, such that it changed from $14.3 \%$ in the first year to $38.1 \%$ in the third year and thereafter ${ }^{28}$. Furthermore, in Marino's study on Chilean older adults, when participants were questioned about quality of life in relation to edentulism, $55.8 \%$ described it as excellent and very good while only $6 \%$ described it as bad or very bad $^{29}$. The elderly participants in our study repeatedly mentioned the causes of edentulism and mostly stressed their lack of sufficient knowledge from a young age on how to take proper care of their teeth. A similar study on elderly people in southern Brazil revealed that a lack of proper policy regarding dental health, and lack of knowledge, meant that they would readily have damaged teeth extracted $^{30}$. Participants in our study used several mechanisms to manage problems associated with edentulism such as changing the constituency of food or deeming edentulism as a natural part of old age. Another study examined the role of adaptation to edentulism and making changes in eating style such as pureeing food, mincing or boiling as cheap alternatives to expensive rehabilitation techniques $^{31}$. Conversely, elderly participants in 
our study mentioned uncertainty in choosing the type and time for treatment of dental problems. In a study, many believed that application of dental rehabilitation equipment did not necessarily improve their diet and that even having a denture fitted could prevent an individual from authentic experiences tasting food ${ }^{32}$. Fear and anxiety of dental treatment and long periods of waiting for treatment of damaged teeth had led elderly people in southern Brazil to have their teeth pulled out ${ }^{30}$. However, in our study, it seems that apart from the fear and anxiety associated with dental treatment, priorities in the lives of the older adults' interviewed in this study were to help others, take the pilgrimage (based on their religious and traditional beliefs) and financial issues. Some participants mentioned the cost of treatment as an important consideration before embarking on dental treatment. Cost and convenience were barriers to oral health among a sample of older New Zealanders ${ }^{16}$. In Another study showed that in Istanbul, more than one-third of 121 older participants during the last five to 10 years had not taken any action to treat dental problems due to cost and fear, and more than two-thirds of them had used a denture only when eating ${ }^{33}$. In Iran, there is inadequate dental insurance and a lack of dental follow-up facilities to cover/compensate for the cost of dental treatment. Of course, some older people in our study were faced with several physical and functional side effects (such as biting and nocturnal dyspnoea) caused by a loss of a large number of teeth, such that interviews revealed that function of teeth was considered more important to than losing any other body part. Also, in a study by Saintrain, participants answered the question: 'What is your major problem related to losing your teeth?', most of them had concerns physical effects such as the ability to bite food and problems eating tough food rather than social aspects such as speech that may be related to edentulism, difficulty pronouncing some words and feelings of shyness when confronting their partners were also mentioned ${ }^{11}$. Kneckt reported in his study that edentulism caused people to use a hand to cover their mouth when speaking, or to look down because of feelings of embarrassment ${ }^{34}$. In addition, Srislapanan and Heinonen reported in their studies that edentulism affected people's relations with society and family and that the condition could lead to depression, sadness and isolation ${ }^{35,36}$. Most of the participants in our study were in need of dental rehabilitation but after a long period of time after their first tooth loss and that their remaining teeth were very rare. Therefore, it is necessary to socialise all people in such a way that as far as possible people should grow old with their natural set of teeth remaining and be more aware of the consequences of edentulism. In this regard, it is necessary to develop oral rehabilitation programs, especially for the elderly ${ }^{27}$. Another study emphasised the need for more investigations to facilitate better recognition of the nature of relationships to determine preventive strategies $^{37}$.

Based on the results of this study, better evidence-based practice and interventions could be planned to normalise and balance people's oral health expectations especially at this stage of life; appropriate follow-up systems and social health nursing roles could also be redefined.

It seems necessary to first educate older adults on how to take care of and save their remaining teeth so that they can keep them for longer in old age; and secondly, proactive attention to dental disorders and setting oral health as a priority of health policy. Moreover, the present study focused on elderly people who had been suffering edentulism for some years. Nevertheless, those with recent experience of tooth loss or with different types and numbers of lost teeth may have different views or experiences than those participants interviewed in the current study. Also, it is necessary to recognise the concept of healthy eating in relation to edentulism.

\section{Conclusion}

The present study revealed that elderly people's perceptions of partial edentulism, and in fact the transition from being OK to not OK with tooth loss comprised of four themes: gradual realisation of the need to deal with the problem, the search for dental health information, the challenge of adaptation and a tendency towards dental rehabilitation. It seems that the main point of our study on older people's perspectives on edentulism refers to an edentulous crisis event, specifically in the functioning of teeth in chewing and talking; and the more that they could do these two activities (chewing and talking) at an acceptable level, the more they were satisfied with their nutritional status and their level of general health.

\section{Acknowledgements}

The researchers would like to express their gratitude and appreciation to the Deputy of Research of Bushehr University of Medical Sciences and all the elderly people who participated in this study. 


\section{References}

1. Bianco VC, Rubo JH. Aging, Oral Health and Quality of Life. Croatia: INTECH Open Access Publisher, 2012.

2. Eliopoulos C. Gerontological Nursing, 8th edn. China: Wolters Kluwer Health: Lippincott Williams \& Wilkins, 2013. ISBN 978-1-45117277-5.

3. Modanloo M, Ziaea T, Behnampour N. Dental health status in elderly (Gorgan-Iran). J Gorgan Univ Med Sci 2010; 12: 68-73.

4. Lee JS, Weyant RJ, Corby $\mathbf{P}$, Kritchevsky SB, Harris TB, Rooks $\mathbf{R}$ et al. Edentulism and nutritional status in a biracial sample of wellfunctioning, community-dwelling elderly: the health, aging, and body composition study. Am J Clin Nutr 2004; 79: 295-302.

5. McGarry TJ, Nimmo A, Skiba JF, Ahlstrom RH, Smith CR, Koumjian JH et al. Classification system for partial edentulism. J Prosthodont 2002; 11: 181-93.

6. Bratu E, Bratu D, Antonie S. Classification systems for partial edentulism. J Oral Health Dent Manage Black Sea Countries 2007; 4: 50-5.

7. Carr AB, Brown DT. McCracken's Removable Partial Prosthodontics, 12th edn. St. Louis, MO: Elsevier Health Sciences, Mosby, 2010. ISBN: 978-0323-06990-8.

8. Moshref R, Hashempour A. Prevalence of partial edentulous based on Kennedy classification in Yazd. J Islam Dent Assoc Iran (JIDA) 2002; 14: 15-24.

9. Ettinger RL. Demography and dental needs, an international perspective. Gerodontology 1993; 10: 3-9.

10. Niesten $\mathbf{D}$, van Mourik $\mathbf{K}$, van der Sanden W. The impact of having natural teeth on the QoL of frail dentulous older people. A qualitative study. BMC Public Health 2012; 12: 839.

11. Saintrain MVDL, de Souza EHA. Impact of tooth loss on the quality of life. Gerodontology 2012; 29: e6326.

12. Andrade FB, Lebrao ML, Santos JLF, Teixeira DSDC, Oliveira Duarte YA. Relationship between oral health-related quality of life, oral health, socioeconomic, and general health factors in elderly Brazilians. J Am Geriatr Soc 2012; 60: 1755-60.
13. Khadem P, Jabbarifar E, Maroofi V, Feiz A. The effect of using dentures in the improvement of lifestyle among the elderly population of Isfahan, Iran. J Isfahan Dent School 2009; 5: 148-55.

14. Kikutani T, Yoshida M, Enoki H, Yamashita Y, Akifusa S, Shimazaki $\mathbf{Y}$ et al. Relationship between nutrition status and dental occlusion in community-dwelling frail elderly people. Geriatr Gerontol Int 2013; 13: 50-4.

15. Lopez-Jornet $\mathbf{P}$, Saura-Perez $\mathbf{M}$, Llevat-Espinosa $\mathbf{N}$. Effect of oral health dental state and risk of malnutrition in elderly people. Geriatr Gerontol Int 2013; 13: 43-9.

16. Gregory J, Thomson WM, Broughton JR, Cullinan MP, Seymour GJ, Kieser JA et al. Experiences and perceptions of oral health and oral health care among a sample of older New Zealanders. Gerodontology 2012; 29: 54-63.

17. Müller F, Naharro M, Carlsson GE. What are the prevalence and incidence of tooth loss in the adult and elderly population in Europe? Clin Oral Implants Res 2007; 18 (s3): 2-14.

18. Zarb GA, Bolender CL, Eckert S, Fenton A, Jacob R, MericskeStern R. Prosthodontic treatment for edentulous patients: Complete Dentures and Implant Supported Prostheses, 12th edn. St Louis, MO: Elsevier Health Sciences, Mosby, 2003.

19. Thomson WM. Monitoring edentulism in older New Zealand adults over two decades: a review and commentary. Int J Dent 2012; 2012: Article ID 375407, 4 pages.

20. Holloway I, Wheeler S. Qualitative Research in Nursing and Healthcare. Australia: Wiley-Blackwell, 2002.

21. Käyser A. Shortened dental arches and oral function. J Oral Rehabil 1981; 8: 457-62.

22. Hill J. Report on the shortened dental arch concept. BDS Elective. Report, 2007. Available at: http://hdl.handle.net/1905/756 (last accessed 9 October 2016).

23. Khan S, Musekiwa A, Chikte UM, Omar R. Differences in functional outcomes for adult patients with prosthodontically-treated anduntreated shortened dental arches: a systematic review. PLoS One 2014; 9: e101143.

24. Graneheim UH, Lundman B. Qualitative content analysis in nursing research: concepts, procedures and measures to achieve trustworthiness. Nurse Educ Today 2004; 24: 105-12.

25. Burns N, Groove ST. The Practice of Nursing Research, Conduct, Critique and Utilization, 5th edn. Philadelphia, PA: Elsevier Saunders, 2005.

26. Polit DF, Beck CT. Essentials of Nursing Research, Methods, Appraisal, and Utilization, 9th edn. China: Lippincott Williams and Wilkins, 2012.

27. Casotti CA, de Andrade Lima L, Filho DLG, Francisco KMS. Selfperception and oral health conditions of the elderly in a small town. RGO 2012; 60: 187-93.

28. Davis D, Fiske J, Scott B, Radford $\mathbf{D}$. Prosthetics: the emotional effects of tooth loss: a preliminary quantitative study. Br Dent J 2000; 188: 503-6.

29. Mariño R, Albala C, Sanchez H, Cea X, Fuentes A. Self-assessed oral-health status and quality of life of older Chilean. Arch Gerontol Geriatr 2013; 56: 513-7.

30. De Marchi RJ, Leal AF, Padilha DM, Brondani MA. Vulnerability and the psychosocial aspects of tooth loss in old age: a Southern Brazilian study. J Cross Cult Gerontol 2012; 27: 239-58.

31. Johannsen A, Westergren A, Johannsen G. Dental implants from the patient's perspective: transition from tooth loss, through amputation to implants-negative and positive trajectories. J Clin Periodontol 2012; 39: $681-7$.

32. Brondani M. The voice of the elderly in accepting alternative perspectives on oral health. Community Dent Health 2010; 27: 139.

33. Ozkan Y, Özcan M, Kulak Y, Kazazoglu E, Arikan A. General health, dental status and perceived dental treatment needs of an elderly population in Istanbul. Gerodontology 2011; 28: 28-36.

34. Kneckt MC, Keinänen-Kiukaanniemi SM, Knuuttila ML, Syrjälä AMH. Self-esteem as a characteristic of adherence to diabetes and dental self-care regimens. J Clin Periodontol 2001; 28: 175-80.

35. Srisilapanan $\mathbf{P}$, Sheiham A. The prevalence of dental impacts on daily performances in older people in Northern Thailand. Gerodontology 2001; 18: 102-3. 
36. Heinonen H, Aro AR, Aalto A-M, Uutela A. Is the evaluation of the global quality of life determined by emotional status? Qual Life Res 2004; 13: 1347-56.

37. Lexomboon D, Trulsson $\mathbf{M}$, Wårdh I, Parker MG. Chewing ability and tooth loss: association with cognitive impairment in an elderly population study. $J$ Am Geriatr Soc 2012; 60: 1951-6.

Correspondence to:

Maryam Ravanipour, Faculty of Nursing \& Midwifery, Bushehr University of Medical Sciences,
Rishehr Street, P.O.

Box 7518759577, Bushehr, Iran.

Tel./Fax: +98 7744550187

E-mails: ravanipour@bpums. ac.ir and ravanipour@gmail. com 